\title{
Association between preoperative cervical sagittal deformity and inferior outcomes at 2-year follow-up in patients with adult thoracolumbar deformity: analysis of 182 patients
}

Presented at the 2015 AANS/CNS Joint Section on Disorders of the Spine and Peripheral Nerves

\author{
Justin K. Scheer, BS, ${ }^{1}$ Peter G. Passias, MD, ${ }^{2}$ Alexandra M. Sorocean, MD, ${ }^{2}$ \\ Anthony J. Boniello, MD, ${ }^{2}$ Gregory M. Mundis Jr., MD, ${ }^{3}$ Eric Klineberg, MD, ${ }^{4}$ Han Jo Kim, MD, ${ }^{5}$ \\ Themistocles S. Protopsaltis, MD, ${ }^{2}$ Munish Gupta, MD, ${ }^{4}$ Shay Bess, MD, ${ }^{6}$ \\ Christopher I. Shaffrey, MD, ${ }^{7}$ Frank Schwab, MD, ${ }^{2}$ Virginie Lafage, PhD, ${ }^{2}$ \\ Justin S. Smith, MD, PhD, ${ }^{7}$ Christopher P. Ames, MD, ${ }^{8}$ and the International Spine Study Group
}

\begin{abstract}
1Department of Neurological Surgery, Northwestern University Feinberg School of Medicine, Chicago, Illinois; '2Department of Orthopaedic Surgery, NYU Hospital for Joint Diseases, New York, New York; ${ }^{3}$ San Diego Center for Spinal Disorders, La Jolla; ${ }^{4}$ Department of Orthopaedic Surgery, University of California, Davis, Sacramento, California; ${ }^{5}$ Department of Orthopaedic Surgery, Hospital for Special Surgery, New York, New York; ${ }^{6}$ Rocky Mountain Hospital for Children, Denver, Colorado; ${ }^{7}$ Department of Neurosurgery, University of Virginia Health System, Charlottesville, Virginia; and ${ }^{8}$ Department of Neurological Surgery, University of California, San Francisco, California
\end{abstract}

OBJECTIVE A high prevalence of cervical deformity (CD) has been identified among adult patients with thoracolumbar spinal deformity undergoing surgical treatment. The clinical impact of this is uncertain. This study aimed to quantify the differences in patient-reported outcomes among patients with adult spinal deformity (ASD) based on presence of CD prior to treatment.

METHODS A retrospective review was conducted of a multicenter prospective database of patients with ASD who underwent surgical treatment with 2-year follow-up. Patients were grouped by the presence of preoperative CD: 1) cervical positive sagittal malalignment (CPSM) C2-7 sagittal vertical axis $\geq 4 \mathrm{~cm}$; 2) cervical kyphosis (CK) C2-7 angle $>0$; 3) CPSM and CK (BOTH); and 4) no baseline CD (NONE). Health-related quality of life (HRQOL) scores included the Physical Component Summary and Mental Component Summary (PCS and MCS) scores of the 36-Item Short Form Health Survey (SF-36), Oswestry Disability Index (ODI), Scoliosis Research Society-22 questionnaire (SRS-22), and minimum clinically important difference (MCID) of these scores at 2 years. Standard radiographic measurements were conducted for cervical, thoracic, and thoracolumbar parameters.

RESULTS One hundred eighty-two patients were included in this study: CPSM, 45; CK, 37; BOTH, 16; and NONE, 84. Patients with preoperative $C D$ and those without had similar baseline thoracolumbar radiographic measurements and similar correction rates at 2 years. Patients with and without preoperative CD had similar baseline HRQOL and on average both groups experienced some HRQOL improvement. However, those with preoperative CPSM had significantly worse postoperative ODI, PCS, SRS-22 Activity, SRS-22 Appearance, SRS-22 Pain, SRS-22 Satisfaction, and SRS-22 Total score, and were less likely to meet MCID for ODI, PCS, SRS-22 Activity, and SRS-22 Pain scores with the following ORs and 95\% Cls: ODI 0.19 (0.07-0.58), PCS 0.17 (0.06-0.47), SRS-22 Activity 0.23 (0.09-0.62), SRS-22 Pain 0.20

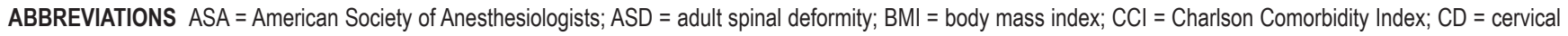
deformity; $\mathrm{CK}=$ cervical kyphosis; $\mathrm{CL}=$ cervical lordosis; $\mathrm{CPSM}=$ cervical positive sagittal malalignment; $\mathrm{EBL}=$ estimated blood loss; HRQOL = health-related quality of life; LL = lumbar lordosis; LOS = length of hospital stay; MCID = minimum clinically important difference; MCS = Mental Component Summary; ODI = Oswestry Disability Index; PCS = Physical Component Summary; PI-LL = mismatch between pelvic incidence and lumbar lordosis; PT = pelvic tilt; SF-36 = 36-Item Short Form Health Survey; SRS-22 = Scoliosis Research Society-22 questionnaire; SVA = sagittal vertical axis; T1S = T-1 slope; T1S-CL = mismatch between T-1 slope and cervical lordosis; TK = thoracic kyphosis.

SUBMITTED October 28, 2014. ACCEPTED March 26, 2015.

INCLUDE WHEN CITING Published online September 11, 2015; DOI: 10.3171/2015.3.SPINE141098. 
(0.08-0.53), and SRS-22 Appearance 0.34 (0.12-0.94). Preoperative CK did not have an effect on outcomes. Interestingly, despite correction of the thoracolumbar deformity, $53.3 \%$ and $51.4 \%$ of patients had persistent CPSM and persistent $\mathrm{CK}$, respectively.

\begin{abstract}
CONCLUSIONS Patients with thoracolumbar deformity without preoperative CD are likely to have greater improvements in HRQOL after surgery than patients with concomitant preoperative CD. Cervical positive sagittal alignment in adult patients with thoracolumbar deformity is strongly associated with inferior outcomes and failure to reach MCID at 2-year follow-up despite having similar baseline HRQOL to patients without CD. This was the first study to assess the impact of concomitant preoperative cervical malalignment in adult patients with thoracolumbar deformity. These results can help surgeons educate patients at risk for inferior outcomes and direct future research to identify an etiology and improve patient outcomes. Investigation into the etiology of the baseline cervical malalignment may be warranted in patients who present with thoracolumbar deformity.
\end{abstract}

http://thejns.org/doi/abs/10.3171/2015.3.SPINE141098

KEY WORDS adult spinal deformity; cervical deformity; health-related quality of life; minimum clinically important difference; cervical sagittal alignment; cervical sagittal vertical axis

I NCREASINGLY, the management of adult spinal deformity (ASD) is considered from a global perspective..$^{1,14,16,26}$ The majority of literature regarding the management of ASD has focused on the thoracolumbar region with little regard for the adjacent regions. Several recent studies have demonstrated that regional spinal alignment and pathology can affect other spinal regions. These studies highlight the importance of considering the entire spine when planning for the surgical correction of ASD.

Ames et al. ${ }^{1}$ reported a significant chain of correlations beginning with pelvic alignment parameters that linked the pelvis with lumbar lordosis (LL), thoracic kyphosis (TK), and cervical lordosis (CL) in normal volunteers. Surgical correction in 1 region may result in an alignment change in another region. Klineberg et al. ${ }^{16}$ found changes in thoracic and lumbar alignment for unfused segments following thoracic and lumbar osteotomies, respectively. Similarly, Lafage et al..$^{18}$ reported a spontaneous increase in unfused TK following lumbar 3-column osteotomies. Lastly, both Smith et al..$^{26}$ and Ha et al. ${ }^{14}$ reported spontaneous improvement of cervical alignment after correction of global sagittal malalignment following lumbar pedicle subtraction osteotomy. These studies focus on thoracolumbar deformities. Not until recently has cervical deformity (CD) been investigated more thoroughly.

The cervical spine is a complex region. It not only supports the mass of the head, but it also allows the widest range of motion relative to the rest of the spine. ${ }^{22}$ Furthermore, the cervical spine plays a pivotal role in influencing adjacent and global spinal alignment as compensatory changes occur to maintain horizontal gaze. Cervical malalignment is debilitating and has adverse effects on the overall functioning and health-related quality of life (HRQOL) of the patient., 72,22,24,27,29 Tang and colleagues ${ }^{27}$ investigated cervical positive sagittal malalignment (CPSM) and disability following posterior cervical fusion in 113 patients. The authors found that increasing CPSM correlates with increasing disability and determined a CPSM threshold of $4 \mathrm{~cm}$, at which severe disability occurs. Moreover, Smith and colleagues ${ }^{24}$ found a significant correlation between CPSM and severity of myelopathy in patients with cervical spondylotic myelopathy.
There has been a shift from the regional view of the spine to a more global perspective, and recent work has found concomitant spinal deformities in patients. Specifically, there is a high prevalence of CD among adult patients with thoracolumbar spinal deformity. A study by Smith et al ${ }^{25}$ determined the prevalence of concomitant $\mathrm{CD}$ in a large thoracolumbar ASD population of 470 patients. Cervical deformity was defined as cervical kyphosis (CK) or CPSM defined by a C2-7 sagittal vertical axis (SVA) of $\geq 4 \mathrm{~cm}$. The prevalence of CK and CPSM were found to be $31 \%$ and $29 \%$, respectively, with the prevalence of CK and/or CPSM being 53\%. Given the high prevalence of concomitant cervical malalignment, it has yet to be determined if this has any impact on HRQOL outcomes or the likelihood of reaching a minimum clinically important difference (MCID) ${ }^{2,3,6}$ following surgical correction of the thoracolumbar deformities. Therefore, the purpose of the present study was to determine the effect of concomitant baseline CD on HRQOL outcomes and the probability of reaching an MCID 2 years after surgical correction of adult thoracolumbar spinal deformity.

\section{Methods \\ Patient Population}

This study is a retrospective review of a prospective multicenter ASD database composed of 11 sites across the US. All patients were enrolled into a protocol approved by the institutional review board at each site. Inclusion criteria for the database were age $>18$ years and presence of spinal deformity, as defined by scoliosis Cobb angle $\geq 20^{\circ}$, SVA $\geq 5 \mathrm{~cm}$, pelvic tilt $(\mathrm{PT}) \geq 25^{\circ}$, and $/$ or TK $\geq 60^{\circ}$. Exclusion criteria included spinal deformity of a neuromuscular etiology and presence of active infection or malignancy. In addition to the above criteria, patients with available cervical and thoracolumbar radiographs were included.

\section{Data Collection, Radiographic Assessment, and HRQOL}

The demographic and clinical data included patient age, sex, body mass index (BMI), and Charlson Comorbidity Index (CCI). ${ }^{5}$ Surgical data collected included American Society of Anesthesiologists (ASA) physical status clas- 
sification, length of hospital stay (LOS), operating room time, and estimated blood loss (EBL).

Standardized HRQOL instruments included the Oswestry Disability Index (ODI), 36-Item Short Form Health Survey (SF-36), and the Scoliosis Research Society-22 questionnaire (SRS-22). Two standard summary scores were calculated based on the SF-36: the Physical Component Summary (PCS) and the Mental Component Summary (MCS). To place HRQOL outcomes in a clinically relevant context, MCID values have been established for the HRQOL instruments..$^{2,8}$ Analysis for differences in the proportions of patients across groups reaching MCID for each HRQOL measure was also conducted. The MCID values used in the present study included ODI (-15), PCS (5.2), SRS-22 Activity (0.375), SRS-22 Pain (0.587), SRS22 Appearance (0.8), and SRS-22 Mental (0.42). ${ }^{3,6,8}$

Full-length free-standing lateral spine radiographs (36in cassette) at baseline and at 6-week, 1-year, and 2-year follow-up were analyzed using validated software ${ }^{4,21}$ (SpineView, ENSAM, Laboratory of Biomechanics). All radiographic measures were performed at a central location based on standard techniques ${ }^{19}$ and included coronal Cobb angles of thoracic and lumbar curves, TK (T2-12; Cobb angle between superior endplate of $\mathrm{T}-2$ and inferior endplate of T-12), SVA (C-7 plumb line relative to S-1), $\mathrm{PT}$, and the mismatch between pelvic incidence and LL (PI-LL). Based on these radiographic parameters, patients were additionally stratified by the SRS-Schwab ASD classification. ${ }^{23}$ In this classification, the coronal curve type of a spine is determined by the maximal coronal angle measured according to standard Cobb technique. The 4 curve types included a Type $\mathrm{T}$ spine with a thoracic major curve $>30^{\circ}$ (the spinal level of the curve apex was at T-9 or above) and a lumbar curve $<30^{\circ}$; Type L with a lumbar or thoracolumbar major curve $>30^{\circ}$ (the spinal level of the curve apex was at T-10 or lower) and a thoracic curve $<30^{\circ}$; Type $\mathrm{D}$ with a double major curve (i.e., 1 Type $\mathrm{T}$ and 1 Type L curve), with each curve $>30^{\circ}$; and Type $\mathrm{N}$ with no coronal curve $>30^{\circ}$ (no major coronal deformity).

Additional cervical radiographic parameters included CL for C2-7, cervical SVA (measured from offset between the plumb line from the center of the $\mathrm{C}-2$ lower endplate to the posterosuperior corner of C-7), T-1 slope (T1S), and the mismatch between T1S and CL (T1S-CL). Patients were classified into 4 groups based on the presence or absence of preoperative CD: 1) only CPSM (C2-7 SVA $\geq 4 \mathrm{~cm}) ; 2$ ) only CK (C2-7 Cobb angle $>0^{\circ}$ ); 3 ) both CPSM and CK (BOTH); and 4) no preoperative CD (NONE). Additionally, patients were grouped based on persistent deformity (Persistent CPSM or CK) or spontaneous correction of the deformity at 2 years (Corrected CPSM or CK), or if they remained without deformity (Persistent NONE).

\section{Statistical Analyses}

Continuous variables were described by the mean and SD. Normality of data was determined using the ShapiroWilk test. Comparison of means between the groups initially included an ANOVA or Kruskal-Wallis test where appropriate, which was followed by pairwise comparisons using Tukey's Honest Significant Difference test to control for Type I error or Wilcoxon rank-sum tests where appropriate. Initial frequency analysis for meeting MCID between patients with preoperative $\mathrm{CD}$ and those patients without was conducted using Pearson's chi-square analysis. In addition, multivariable binomial logistic regressions were conducted to assess the impact of preoperative CD (CPSM vs NONE and CK vs NONE) on the rates of meeting MCID for each of the HRQOL measures. Covariates in the models included age; sex; CCI; BMI; the respective baseline HRQOL measure (i.e., baseline ODI for the ODI MCID model); and baseline PT, PI-LL, and SVA. ORs with the corresponding $95 \%$ CIs were reported. All statistical analyses were conducted using commercially available software (SPSS v22, IBM), and the level of significance was set at $\mathrm{p}<0.05$ for all analyses.

\section{Results}

\section{Patient Population}

Of the available patients, 286 were eligible for 2-year follow-up: 235 (82.2\%) had complete baseline data and 2-year radiographic and clinical follow-up. Of those, 182 patients (77.4\% of 235) had 36-in radiographs that included the cervical spine and were thus available for measurement. None of the patients had any treatment involving their cervical spine. All surgical treatment was localized to correction of the thoracolumbar deformity. Of the total 182 patients included in the present study, those with preoperative CD included 45 patients (24.7\%) with CPSM, 37 (20.3\%) with CK, $16(8.8 \%)$ with BOTH, and 84 (46.2\%) with NONE (Table 1). Due to the small number of patients in the BOTH group, analyses were not conducted for this group. Patients with $\mathrm{CK}$ were significantly younger than those without ( $p<0.05$ for both). No other significant differences were noted between groups for the demographic variables. The distribution of SRS-Schwab coronal curve types was sta-

TABLE 1. Baseline patient demographic data and SRS-Schwab classification for CPSM, CK, and NONE groups*

\begin{tabular}{lccc}
\hline \multicolumn{1}{c}{ Variable } & CPSM & CK & NONE \\
\hline No. of patients & 45 & 37 & 84 \\
\hline Age, yrs & $57.5 \pm 13.2$ & $46.5 \pm 15.3$ & $56.1 \pm 13.9$ \\
\hline Female/male & $37: 8$ & $33: 4$ & $37: 8$ \\
\hline BMl, kg/cm ${ }^{2}$ & $28.1 \pm 5.2$ & $25.4 \pm 5.4$ & $27 \pm 5.5$ \\
\hline ASA & $2.2 \pm 0.6$ & $2.2 \pm 0.8$ & $2.3 \pm 0.6$ \\
\hline CCl & $1.5 \pm 1.9$ & $0.8 \pm 1.2$ & $1.4 \pm 1.5$ \\
\hline LOS, days & $8.2 \pm 2.9$ & $7.2 \pm 2.8$ & $7.4 \pm 3.1$ \\
\hline OR time, hrs & $417.2 \pm 152.5$ & $391.3 \pm 141.5$ & $394.9 \pm 122.7$ \\
\hline EBL, ml & $1848 \pm 1476.6$ & $1588.6 \pm 1431.8$ & $1530.7 \pm 1259$ \\
\hline $\begin{array}{c}\text { SRS-Schwab } \\
\text { coronal curve } \\
\text { type, no. of } \\
\text { patients (\%) }\end{array}$ & & & \\
\hline $\mathrm{N}$ & $14(31.1)$ & $6(16.2)$ & $19(22.6)$ \\
\hline $\mathrm{T}$ & $2(4.4)$ & $4(10.8)$ & $3(3.6)$ \\
\hline $\mathrm{L}$ & $15(33.3)$ & $13(35.1)$ & $31(36.9)$ \\
\hline $\mathrm{D}$ & $14(31.1)$ & $14(37.8)$ & $31(36.9)$ \\
\hline
\end{tabular}

$\mathrm{OR}=$ operating room.

* Unless otherwise indicated, values are expressed as the mean \pm SD. 
TABLE 2. Complete standard HRQOL measures for CPSM, CK, and NONE groups at baseline and at 2 years*

\begin{tabular}{ccccccccccc}
\hline \multirow{2}{*}{ Time } & Group & ODI & PCS & MCS & $\begin{array}{c}\text { SRS-22 } \\
\text { Activity }\end{array}$ & SRS-22 Pain & $\begin{array}{c}\text { SRS-22 } \\
\text { Appearance }\end{array}$ & $\begin{array}{c}\text { SRS-22 } \\
\text { Mental }\end{array}$ & $\begin{array}{c}\text { SRS-22 } \\
\text { Satisfaction }\end{array}$ & SRS-22 Total \\
\hline Preop & CPSM & $43.5 \pm 19.5$ & $32.5 \pm 9.3$ & $44.2 \pm 13.2$ & $2.9 \pm 1$ & $2.4 \pm 0.9$ & $2.3 \pm 0.7$ & $3.5 \pm 1$ & $2.8 \pm 1.1$ & $2.8 \pm 0.7$ \\
\cline { 2 - 11 } & CK & $36.2 \pm 19.4$ & $37.1 \pm 11.1$ & $49.8 \pm 11.1$ & $3.2 \pm 1$ & $2.6 \pm 0.9$ & $2.8 \pm 0.8$ & $3.6 \pm 0.8$ & $3 \pm 1$ & $3.1 \pm 0.7$ \\
\cline { 2 - 11 } & NONE & $39.8 \pm 18.9$ & $33.4 \pm 9.7$ & $45.1 \pm 14.4$ & $3 \pm 0.8$ & $2.5 \pm 0.9$ & $2.5 \pm 0.7$ & $3.5 \pm 0.9$ & $2.7 \pm 1.1$ & $2.9 \pm 0.7$ \\
\hline \multirow{2}{*}{ At 2 yrs } & CPSM & $34.8 \pm 17.6$ & $36.4 \pm 10.8$ & $48.4 \pm 12.5$ & $3.1 \pm 1$ & $2.9 \pm 1$ & $3.4 \pm 1$ & $3.7 \pm 0.9$ & $4 \pm 1$ & $3.3 \pm 0.8$ \\
\cline { 2 - 11 } & CK & $19.7 \pm 18$ & $46.5 \pm 11.6$ & $49.9 \pm 11.7$ & $4 \pm 0.9$ & $3.9 \pm 1.1$ & $4.1 \pm 0.7$ & $4 \pm 0.8$ & $4.5 \pm 0.8$ & $4 \pm 0.7$ \\
\cline { 2 - 11 } & NONE & $23.1 \pm 20.1$ & $42.4 \pm 11.2$ & $51.1 \pm 12.9$ & $3.7 \pm 1$ & $3.6 \pm 1.1$ & $3.8 \pm 0.9$ & $3.9 \pm 0.9$ & $4.4 \pm 0.8$ & $3.8 \pm 0.8$ \\
\hline
\end{tabular}

* Values are presented as the mean $\pm 1 \mathrm{SD}$.

tistically similar between all of the CD groups and NONE $(\mathrm{p}>0.05)$.

\section{Health-Related Quality of Life Analysis}

Patients with CPSM and CK both had statistically similar baseline mean HRQOL for all scores measured compared with NONE ( $p>0.05$ for all, Table 2). The CPSM, CK, and NONE groups all had significant mean improvements in all HRQOL measures at 2 years postoperatively compared with baseline ( $\mathrm{p}<0.05$ for all). At 2 years, CPSM had worse mean HRQOL scores compared with NONE for ODI, PCS, SRS-22 Activity, SRS-22 Appearance, SRS-22 Pain, SRS-22 Satisfaction, and SRS-22 Total score $(\mathrm{p}<0.05$ for all). There were no significant differences in 2-year mean HRQOL scores between patients with CK and NONE ( $p>0.05$ for all).

\section{Minimum Clinically Important Difference Analysis}

Patients with preoperative CPSM were significantly less likely to reach 2-year MCID for ODI, PCS, SRS-22 Activity, SRS-22 Pain, and SRS-22 Appearance than NONE (p $<0.05$ for all, Table 3, Fig. 1). The odds of meeting the MCID from the multivariable binomial logistic regression models for each HRQOL measure were ODI 0.19, PCS 0.17 , SRS-22 Activity 0.23, SRS-22 Pain 0.20, and SRS-22 Appearance 0.34 ( $\mathrm{p}<0.05$ for all, Table 4). Patients with preoperative $\mathrm{CK}$ had statistically similar rates of meeting MCID for all HRQOL compared with NONE ( $p<0.05$ for all, Tables 3 and 4).

\section{Radiographic Analysis}

At baseline, patients with CPSM had statistically similar mean PT and PI-LL compared with NONE ( $p>0.05$,

TABLE 3. Percentage of patients reaching MCID for the various HRQOL measures in the CPSM, CK, and NONE groups

\begin{tabular}{llcc}
\hline & \multicolumn{3}{c}{ No. of Patients (\%) } \\
\cline { 2 - 4 } HRQOL Instrument & \multicolumn{1}{c}{ CPSM } & CK & NONE \\
\hline ODI & $14(31.1)$ & $18(48.6)$ & $43(52.4)$ \\
\hline PCS & $11(29.7)$ & $20(64.5)$ & $46(63.9)$ \\
\hline SRS-22 Activity & $21(50)$ & $23(69.7)$ & $60(72.3)$ \\
\hline SRS-22 Pain & $21(50)$ & $24(72.7)$ & $59(71.1)$ \\
\hline SRS-22 Appearance & $26(63.4)$ & $25(75.8)$ & $66(79.5)$ \\
\hline SRS-22 Mental & $16(39)$ & $14(42.4)$ & $35(42.2)$ \\
\hline
\end{tabular}

Table 5, Fig. 2). Patients with CPSM also had statistically similar mean SVA compared with NONE ( $p>0.05)$. However, patients with CK had significantly smaller mean SVA compared with NONE $(\mathrm{p}<0.05)$. For the baseline cervical and thoracic parameters, CPSM had larger mean C2-7 SVA, CL, T1S, T1S-CL, and TK compared with NONE ( $p<0.05$ for all). The CK group had significantly smaller mean T1S and TK as well as larger mean T1S-CL compared with NONE ( $p<0.05$ for all).

At 2 years, the CPSM, CK, and NONE groups all had significantly improved mean SVA and PI-LL compared with baseline $(\mathrm{p}<0.05)$ but not PT $(\mathrm{p}>0.05$, Table 5, Fig. 2 ). Both the CPSM and CK groups had similar 2-year mean SVA, PT, and PI-LL compared with the NONE group ( $\mathrm{p}$ $>0.05$ for all), as well as similar amounts of correction for each measure ( $p>0.05$ for all) with the exception of those patients with CK, who still had a smaller mean SVA than NONE ( $\mathrm{p}<0.05)$. Regarding the cervical and thoracic parameters, CPSM continued to have elevated mean $\mathrm{C} 2-7$ SVA, CL, T1S, and TK compared with NONE $(p<0.05$ for all). Similarly, the CK group continued to have lower mean CK, T1S, T1S-CL, and TK at 2 years compared with NONE ( $p<0.05$ for all).

When stratifying the patients by persistent or spontaneously corrected CD at 2 years, $53.3 \%$ of patients with preoperative CPSM and $51.4 \%$ of patients with preoperative CK had persistent CPSM and CK, respectively (Table 6). Due to the small number of patients in the persistent and

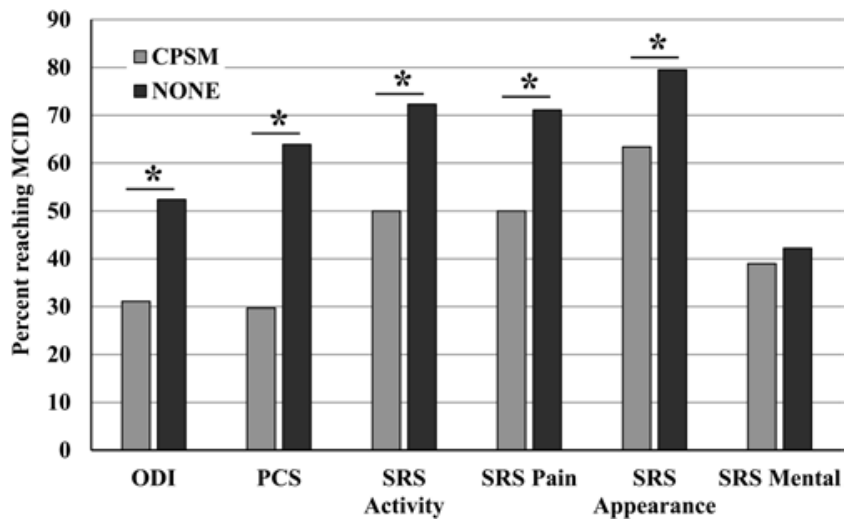

FIG. 1. The percentage of patients meeting MCID in the various HRQOL measures for patients with baseline cervical SVA $\geq 4 \mathrm{~cm}$ (CPSM) and patients without baseline CPSM or CK (NONE). Values marked with an asterisk are statistically significant with $p<0.05$. 
TABLE 4. ORs for reaching MCID at 2 years in the listed HRQOL measures for patients with preoperative cervical malalignment compared with those without

\begin{tabular}{|c|c|c|}
\hline \multirow[b]{2}{*}{ HRQOL Measure } & \multicolumn{2}{|c|}{$\mathrm{OR}(95 \% \mathrm{Cl})$} \\
\hline & Preop CPSM vs NONE* & Preop CK vs NONE \\
\hline ODI & $0.19(0.07-0.58)$ & $0.94(0.37-2.42)$ \\
\hline PCS & $0.17(0.06-0.47)$ & $1.16(0.42-3.22)$ \\
\hline SRS-22 Activity & $0.23(0.09-0.62)$ & $1.43(0.52-3.91)$ \\
\hline SRS-22 Pain & $0.20(0.08-0.53)$ & $0.89(0.31-2.54)$ \\
\hline SRS-22 Appearance & $0.34(0.12-0.94)$ & $1.21(0.37-3.99)$ \\
\hline SRS-22 Mental & $0.76(0.27-2.12)$ & $1.35(0.49-3.72)$ \\
\hline
\end{tabular}

* Values in bold are significant.

corrected groups, analyses were not conducted. A case example is provided in Fig. 3.

\section{Discussion}

There is a high prevalence of CD among adult patients with thoracolumbar spinal deformity, with rates as high as $31 \%$ and $29 \%$ for CK and CPSM, respectively, and $53 \%$ for either. ${ }^{25}$ Given this high prevalence of concomitant cervical malalignment, it has yet to be determined if this has any impact on HRQOL outcomes. The present study determined the effect of concomitant baseline CD (CPSM and $\mathrm{CK}$ ) on HRQOL outcomes and the probability of reaching MCID at 2 years following surgical correction of adult thoracolumbar spinal deformity. Despite experiencing significant improvements in both HRQOL scores and thoracolumbar sagittal radiographic correction, preoperative CPSM is strongly associated with worse HRQOL outcomes and failure to reach MCID at 2-year follow-up. There were no differences in HRQOL or thoracolumbar radiographic parameters preoperatively between patients with and without CD. Moreover, the majority of these patients continued to have cervical malalignment at 2 years.

At baseline, all of the demographic differences were similar between patients with and without preoperative cervical malalignment, with the exception of CK. Patients with CK were significantly younger by an average of 10

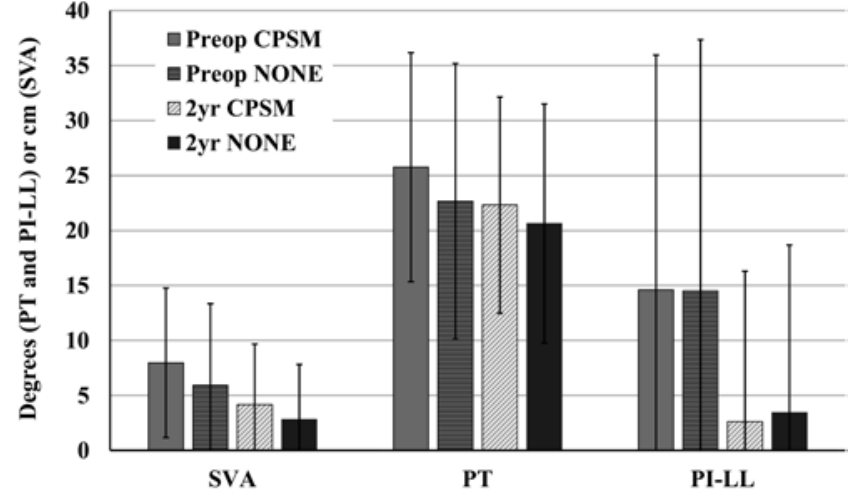

FIG. 2. The mean preoperative and 2-year postoperative thoracolumbar radiographic parameters are shown for patients with preoperative CPSM defined by cervical SVA $\geq 4 \mathrm{~cm}$ and those without any preoperative CD (NONE). There were no significant differences between the 2 groups for preoperative and 2-year postoperative values.

years. This result is in line with both Park et al. ${ }^{20}$ and Smith et al. ${ }^{25}$ The study by Park and colleagues assessed the effect of age on cervical sagittal alignment in 100 asymptomatic subjects and found that the $\mathrm{C} 2-7$ lordosis increased with age. Smith et al. also found that patients with CK were significantly younger than those without $\mathrm{CK}$ in a large population of adult patients with thoracolumbar spinal deformity. Increasing age is probably a large factor contributing to the progressive increase in CL. Interestingly, CPSM did not significantly vary based on age in the present study or in the other 2 studies. ${ }^{20,25}$ Cervical sagittal translation appears to be conserved as patients become older.

All patients had similar mean baseline HRQOL scores regardless of whether they had concomitant cervical malalignment. This is interesting, considering that prior studies have demonstrated that cervical malalignment, especially positive SVA, is associated with poor HRQOL. Tang et al. ${ }^{27}$ investigated CPSM and disability following posterior cervical fusion. The authors found that increasing CPSM correlated with increasing disability and expanded this to define a CPSM threshold of $4 \mathrm{~cm}$, at which severe disability occurs. All patients in the present study were categorized as having CPSM based on this criterion

TABLE 5. Complete radiographic values for preoperative, 2-year follow-up, and 2-year changes from baseline for CPSM, CK, and NONE groups*

\begin{tabular}{|c|c|c|c|c|c|c|c|c|c|}
\hline Timeframe & Group & $\begin{array}{c}\text { C2-7 SVA, } \\
\mathrm{cm}\end{array}$ & $\mathrm{CL}^{\circ} \dagger$ & $\mathrm{T}^{\circ} \mathrm{S}^{\circ}$ & $\mathrm{T} 1 \mathrm{~S}-\mathrm{CL}^{\circ}$ & $\mathrm{TK}^{\circ}$ & C7-S1 SVA, cm & $\mathrm{PT}^{\circ}$ & $\mathrm{PI}-\mathrm{LL}^{\circ}$ \\
\hline \multirow[t]{3}{*}{ Preop } & CPSM & $5.4 \pm 1.2$ & $16.7 \pm 11.5$ & $35.7 \pm 10.9$ & $19.1 \pm 9.4$ & $45.1 \pm 18.3$ & $8.0 \pm 6.8$ & $25.8 \pm 10.4$ & $14.6 \pm 21.4$ \\
\hline & $\mathrm{CK}$ & $2.4 \pm 1.1$ & $-8.3 \pm 6.3$ & $13 \pm 7$ & $21.3 \pm 7.4$ & $23.5 \pm 14.8$ & $1.1 \pm 4.6$ & $19.8 \pm 9.2$ & $8.5 \pm 18.1$ \\
\hline & NONE & $2.6 \pm 0.9$ & $12.9 \pm 11.3$ & $23 \pm 9.3$ & $10 \pm 9.7$ & $31 \pm 15.7$ & $5.9 \pm 7.4$ & $22.7 \pm 12.5$ & $14.5 \pm 22.8$ \\
\hline \multirow[t]{3}{*}{ At $2 \mathrm{yrs}$} & CPSM & $5.0 \pm 1.8$ & $15.7 \pm 14.2$ & $38 \pm 12.2$ & $22.3 \pm 12.9$ & $56.5 \pm 15.7$ & $4.2 \pm 5.5$ & $22.3 \pm 9.8$ & $2.6 \pm 13.7$ \\
\hline & $\mathrm{CK}$ & $2.8 \pm 1.5$ & $-4.6 \pm 13.3$ & $19.6 \pm 10.8$ & $24.2 \pm 10.9$ & $36.9 \pm 17.1$ & $0.3 \pm 4.5$ & $17.8 \pm 9$ & $1 \pm 13.3$ \\
\hline & NONE & $3.0 \pm 1.4$ & $10.4 \pm 15.2$ & $28.4 \pm 11.5$ & $18 \pm 10.3$ & $45.7 \pm 15.4$ & $2.8 \pm 5.0$ & $20.6 \pm 10.9$ & $3.4 \pm 15.2$ \\
\hline \multirow{3}{*}{$\begin{array}{l}\text { 2-yr change } \\
\text { from baseline }\end{array}$} & CPSM & $-0.3 \pm 1.5$ & $-0.9 \pm 10.3$ & $2.3 \pm 10$ & $3.2 \pm 10$ & $-11.4 \pm 16.3$ & $-3.8 \pm 6.5$ & $-3.4 \pm 8.9$ & $-12 \pm 18.6$ \\
\hline & CK & $0.4 \pm 1.4$ & $3.7 \pm 12.8$ & $6.5 \pm 9.5$ & $2.9 \pm 11.4$ & $-13.4 \pm 15.4$ & $-0.8 \pm 4.2$ & $-2 \pm 6.3$ & $-7.5 \pm 15.4$ \\
\hline & NONE & $0.5 \pm 1.3$ & $-2.5 \pm 13.1$ & $5.5 \pm 9.9$ & $8 \pm 11.3$ & $-14.7 \pm 14.4$ & $-3.1 \pm 6.4$ & $-2 \pm 7.6$ & $-11.1 \pm 17.4$ \\
\hline
\end{tabular}

* Values are presented as the mean $\pm 1 \mathrm{SD}$.

$\dagger$ For $C L$, negative values indicate kyphosis. 
TABLE 6. Number and percentage of patients in each group who had persistent, corrected, or new deformity at 2-year follow-up

\begin{tabular}{lcrrccc}
\hline & \multicolumn{5}{c}{ No. of Patients (\%) } \\
\cline { 2 - 7 } Group & Preop & $\begin{array}{r}\text { 2 Yrs Postop, } \\
\text { Persistent }\end{array}$ & $\begin{array}{c}\text { 2 Yrs Postop, } \\
\text { Corrected }\end{array}$ & 2 Yrs Postop, New CPSM & 2 Yrs Postop, New CK & 2 Yrs Postop, New BOTH \\
\hline CPSM & $45(100)$ & $24(53.3)$ & $13(28.9)$ & NA & $4(8.9)$ & $4(8.9)$ \\
\hline CK & $37(100)$ & $19(51.4)$ & $10(27.0)$ & $4(10.8)$ & NA & $4(10.8)$ \\
\hline BOTH & $16(100)$ & $4(25.0)$ & $3(18.8)$ & $4(25.0)$ & $5(31.3)$ & NA \\
\hline NONE & $84(100)$ & $47(56.0)$ & NA & $14(16.7)$ & $19(22.6)$ & $4(4.8)$ \\
\hline
\end{tabular}

$\mathrm{NA}=$ not applicable

of greater than $4 \mathrm{~cm}$. Moreover, Smith and colleagues ${ }^{24}$ found a significant correlation between CPSM and severity of myelopathy in patients with cervical spondylotic myelopathy. It is unknown whether the cervical malalignments in the patients in the present study are primary cervical deformities or compensatory alignment changes from the thoracolumbar malalignment. It is probable that there is a mix of primary deformity and compensatory changes. The compensatory changes may not produce as large of an effect on HRQOL as the primary deformities. Furthermore, it is also possible that the thoracolumbar deformity dominates the patient-reported HRQOL scores and that any affect the cervical spine may have is missed.

Every group in the present study had a significant im- provement in mean HRQOL at 2 years compared with baseline. However, patients with CPSM did not improve as much as those without, as evidenced by the lower 2-year HRQOL scores as well as the lower rates of reaching 2-year MCID. This may be a result of the persistence of cervical malalignment following the thoracolumbar correction that affects the chances of reaching MCID and further improvement in HRQOL, as $53.3 \%$ of the patients had persistent CPSM. Furthermore, significant improvements in sagittal thoracolumbar correction were seen, both in patients with preoperative CPSM and those without. However, the cervical parameters remained abnormal at 2 years in the patients with preoperative CPSM. Therefore, it may be the case that after the disability and pain from
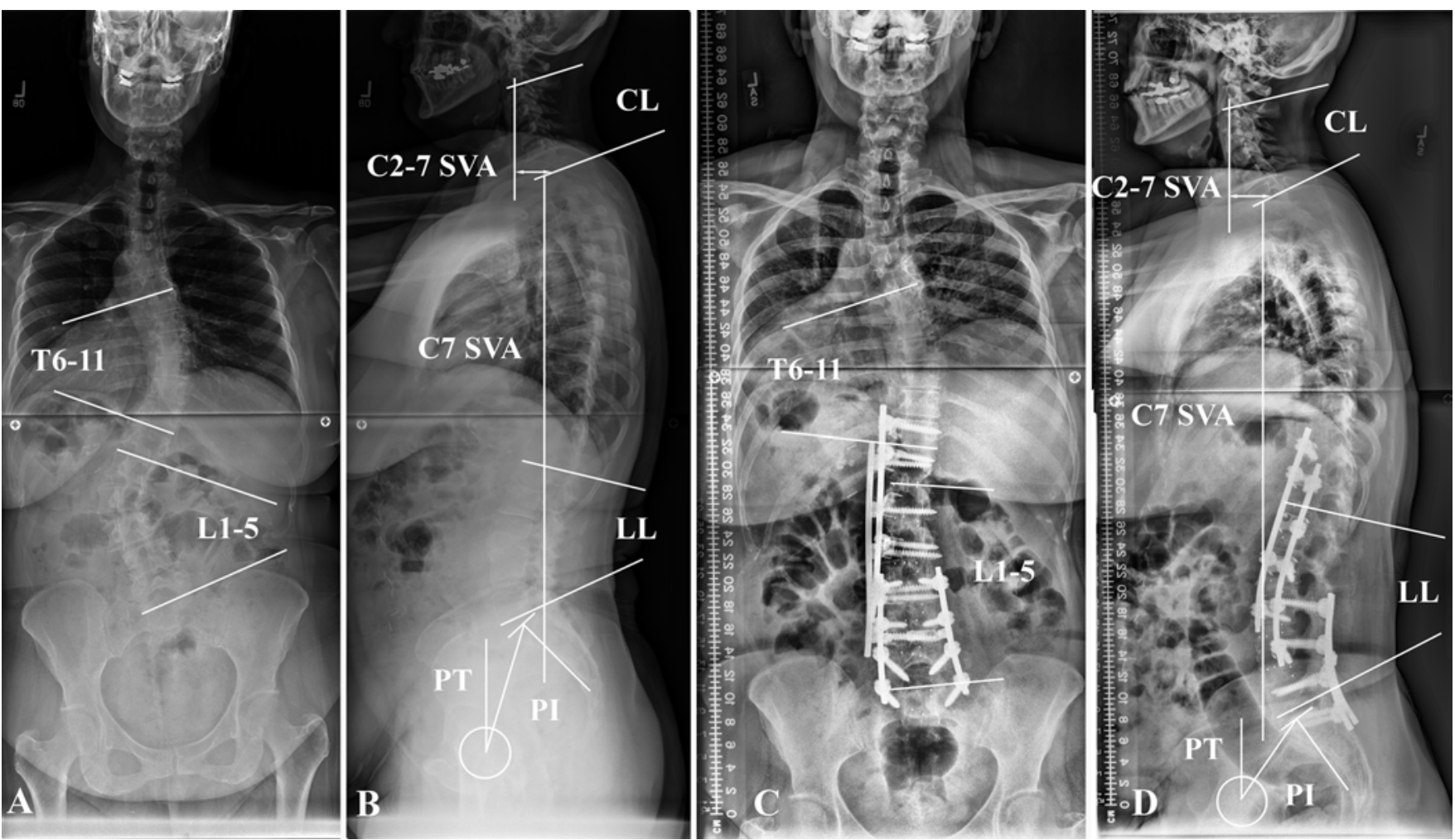

FIG. 3. An example is given of a patient with preoperative CPSM that persisted 2 years after surgery. This patient did not meet any of the 2-year MCID values for all 6 of the HRQOL measures. Preoperative anteroposterior $(\mathbf{A})$ and lateral $(\mathbf{B})$ radiographs are shown with the following values: $\mathrm{T} 6-11 \mathrm{Cobb}=38.2^{\circ}, \mathrm{L} 1-5 \mathrm{Cobb}=43.0^{\circ}, \mathrm{PT}=21.9^{\circ}, \mathrm{PI}=65.3^{\circ}, \mathrm{LL}=61.8^{\circ}, \mathrm{PI}-\mathrm{LL}=3.5^{\circ}, \mathrm{C}-7$ SVA $=-4.6 \mathrm{~mm}$, and C2-7 SVA $=44.4 \mathrm{~mm}$. Two-year anteroposterior $(C)$ and lateral $(D)$ radiographs are shown with the following values: $\mathrm{T} 6-11 \mathrm{Cobb}=24.8^{\circ}, \mathrm{L} 1-5 \mathrm{Cobb}=1.2^{\circ}, \mathrm{PT}=30.4^{\circ}, \mathrm{PI}=66.3^{\circ}, \mathrm{LL}=49.9^{\circ}, \mathrm{PI}-\mathrm{LL}=16.4^{\circ}, \mathrm{C}-7 \mathrm{SVA}=57.4 \mathrm{~mm}, \mathrm{CL}=13.3^{\circ}$, and $\mathrm{C} 2-7 \mathrm{SVA}=44.3 \mathrm{~mm}$. 
the thoracolumbar deformity has been corrected or at least improved, the persistent cervical malalignment may have a larger effect on patients, reducing their 2-year HRQOL and making them less likely to reach 2-year MCID. Another hypothesis could be that a subset of this population also has cervical degenerative disease, with possible pain from that adding to the reduced probability of reaching MCID. Unfortunately, the number of patients in these groups was small and thus prohibited our analysis from further assessing the cause of the inferior HRQOL outcomes. In addition, neck-specific HRQOL measures were not collected, e.g., the Neck Disability Index, because this study stems from a database of patients with thoracolumbar deformity.

It is interesting to note that patients with preoperative CK have HRQOL at both baseline and 2 years postoperatively that is similar to those without CD. However, there exists no clear threshold of CK at which onset of disability can be defined..$^{9-11,13,15,17,28}$ Park and colleagues reported the mean C2-7 sagittal Cobb angles for asymptomatic individuals in their 20s and those older than 60 years to be $-8.98^{\circ} \pm 10.98^{\circ}$ and $-13.70^{\circ} \pm 10.48^{\circ}$, respectively. Based on the definition of $\mathrm{CK}>0^{\circ}$, there may be a population within this definition in which $\mathrm{CK}$ is normal. As evidenced by the present study, it appears that CK (as defined by $>0^{\circ}$ ) does not have an effect on outcomes unless the kyphosis is large enough to result in a cervical SVA greater than $4 \mathrm{~cm}$. Thus, the clinical definition of CK may need to include addition of the cervical SVA or a greater degree of kyphosis. Further work is warranted to define clinically relevant CK.

More work is needed to determine other factors that may be contributing to the observed differences in outcomes. The present study should be viewed as an initial evaluation of the clinical relevance of concomitant CD in patients with thoracolumbar deformity. As mentioned above, it is possible that a subset of these concomitant CDs represents compensatory changes in response to the thoracolumbar deformities and may correct with treatment of the thoracolumbar deformity. This is evidenced by the present study, in which $28.9 \%$ of CPSMs were corrected over the 2-year period. Furthermore, it is also possible that a different subset of these CDs may represent significant pathologies directly affecting the HRQOL measures assessed. Lastly, cervical degenerative disease may also be contributing to these results.

The strengths of the current study include the multicenter design and the complete preoperative and 2-year follow-up data of the patients assessed. Furthermore, patients were enrolled by multiple surgeons from 11 different sites across the US, allowing for better generalizability of the results. Other strengths of this study include the use of MCID, which allows for even further characterization of the impact of the HRQOL parameters studied on patients' clinical improvement. However, there are a few limitations to this study, one of which includes the retrospective design. Despite the retrospective nature of this study, the data used were obtained from a large multicenter prospective database of patients with ASD. Another limitation is that the MCID values used in the present study have not been validated in patients with deformity. Rather, MCID values were taken from studies in which the outcomes were determined from patients with lumbar degenerative disease.
Thus the generalizability of these MCID values is limited, but there is no strong prospective adult deformity study defining MCID values for HRQOL. In addition, neck-specific HRQOL was not recorded. Also, the sample sizes remain too small in the current data set to elucidate a strong etiology for the inferior outcomes in patients with CPSM. However, this is the first study to begin investigating the role of concomitant cervical malalignment in patients with thoracolumbar deformity. It can therefore set the groundwork for further research in this area.

\section{Conclusions}

Concomitant cervical positive sagittal alignment in adult patients with thoracolumbar deformity is strongly associated with inferior outcomes and failure to reach MCID at 2-year follow-up compared with patients without CD. This is despite having similar baseline HRQOL and experiencing significant improvements in HRQOL scores as well as sagittal thoracolumbar radiographic correction. Cervical positive sagittal malalignment persisted at 2 years in $53.3 \%$ of patients. This is the first study to assess the impact of concomitant preoperative cervical malalignment in adult patients with thoracolumbar deformity. These results can help surgeons educate patients at risk for inferior outcomes and direct future research to identify an etiology and improve patient outcomes. Investigation into the etiology of the baseline cervical malalignment may be warranted in patients who present with thoracolumbar deformity.

\section{References}

1. Ames CP, Blondel B, Scheer JK, Schwab FJ, Le Huec JC, Massicotte EM, et al: Cervical radiographical alignment: comprehensive assessment techniques and potential importance in cervical myelopathy. Spine (Phila Pa 1976) 38 (22 Suppl 1):S149-S160, 2013

2. Blondel B, Schwab F, Ungar B, Smith J, Bridwell K, Glassman S, et al: Impact of magnitude and percentage of global sagittal plane correction on health-related quality of life at 2-years follow-up. Neurosurgery 71:341-348, discussion 348, 2012

3. Carreon LY, Sanders JO, Diab M, Sucato DJ, Sturm PF, Glassman SD: The minimum clinically important difference in Scoliosis Research Society-22 Appearance, Activity, And Pain domains after surgical correction of adolescent idiopathic scoliosis. Spine (Phila Pa 1976) 35:2079-2083, 2010

4. Champain S, Benchikh K, Nogier A, Mazel C, Guise JD, Skalli W: Validation of new clinical quantitative analysis software applicable in spine orthopaedic studies. Eur Spine J 15:982-991, 2006

5. Charlson M, Szatrowski TP, Peterson J, Gold J: Validation of a combined comorbidity index. J Clin Epidemiol 47:12451251, 1994

6. Copay AG, Glassman SD, Subach BR, Berven S, Schuler TC, Carreon LY: Minimum clinically important difference in lumbar spine surgery patients: a choice of methods using the Oswestry Disability Index, Medical Outcomes Study questionnaire Short Form 36, and pain scales. Spine J 8:968-974, 2008

7. Etame AB, Wang AC, Than KD, La Marca F, Park P: Outcomes after surgery for cervical spine deformity: review of the literature. Neurosurg Focus 28(3):E14, 2010

8. Glassman SD, Copay AG, Berven SH, Polly DW, Subach BR, Carreon LY: Defining substantial clinical benefit following lumbar spine arthrodesis. J Bone Joint Surg Am 90:18391847,2008 
9. Gore DR, Sepic SB, Gardner GM: Roentgenographic findings of the cervical spine in asymptomatic people. Spine (Phila Pa 1976) 11:521-524, 1986

10. Gore DR, Sepic SB, Gardner GM, Murray MP: Neck pain: a long-term follow-up of 205 patients. Spine (Phila Pa 1976) 12:1-5, 1987

11. Grob D, Frauenfelder H, Mannion AF: The association between cervical spine curvature and neck pain. Eur Spine J 16:669-678, 2007

12. Grosso MJ, Hwang R, Mroz T, Benzel E, Steinmetz MP: Relationship between degree of focal kyphosis correction and neurological outcomes for patients undergoing cervical deformity correction surgery. J Neurosurg Spine 18:537-544, 2013

13. Guo Q, Ni B, Yang J, Liu K, Sun Z, Zhou F, et al: Relation between alignments of upper and subaxial cervical spine: a radiological study. Arch Orthop Trauma Surg 131:857862,2011

14. Ha Y, Schwab F, Lafage V, Mundis G, Shaffrey C, Smith J, et al: Reciprocal changes in cervical spine alignment after corrective thoracolumbar deformity surgery. Eur Spine J 23:552-559, 2014

15. Hardacker JW, Shuford RF, Capicotto PN, Pryor PW: Radiographic standing cervical segmental alignment in adult volunteers without neck symptoms. Spine (Phila Pa 1976) 22:1472-1480, 1997

16. Klineberg E, Schwab F, Ames C, Hostin R, Bess S, Smith JS, et al: Acute reciprocal changes distant from the site of spinal osteotomies affect global postoperative alignment. Adv Orthop 2011:415946, 2011

17. Kuntz C IV, Levin LS, Ondra SL, Shaffrey CI, Morgan CJ: Neutral upright sagittal spinal alignment from the occiput to the pelvis in asymptomatic adults: a review and resynthesis of the literature. J Neurosurg Spine 6:104-112, 2007

18. Lafage V, Ames C, Schwab F, Klineberg E, Akbarnia B, Smith J, et al: Changes in thoracic kyphosis negatively impact sagittal alignment after lumbar pedicle subtraction osteotomy: a comprehensive radiographic analysis. Spine (Phila Pa 1976) 37:E180-E187, 2012

19. O’Brien MF, Kuklo TR, Blanke K, Lenke L (eds): Spinal Deformity Study Group Radiographic Measurement Manual. Memphis, TN: Medtronic Sofamor Danek, 2005

20. Park MS, Moon SH, Lee HM, Kim SW, Kim TH, Lee SY, et al: The effect of age on cervical sagittal alignment: normative data on 100 asymptomatic subjects. Spine (Phila Pa 1976) 38:E458-E463, 2013

21. Rillardon L, Levassor N, Guigui P, Wodecki P, Cardinne L, Templier A, et al: [Validation of a tool to measure pelvic and spinal parameters of sagittal balance.] Rev Chir Orthop Repar Appar Mot 89:218-227, 2003 (Fr)

22. Scheer JK, Tang JA, Smith JS, Acosta FL Jr, Protopsaltis TS, Blondel B, et al: Cervical spine alignment, sagittal deformity, and clinical implications: a review. J Neurosurg Spine 19:141-159, 2013

23. Schwab F, Ungar B, Blondel B, Buchowski J, Coe J, Deinlein D, et al: Scoliosis Research Society-Schwab adult spinal deformity classification: a validation study. Spine (Phila Pa 1976) 37:1077-1082, 2012

24. Smith JS, Lafage V, Ryan DJ, Shaffrey CI, Schwab FJ, Patel AA, et al: Association of myelopathy scores with cervical sagittal balance and normalized spinal cord volume: analysis of 56 preoperative cases from the AOSpine North America Myelopathy study. Spine (Phila Pa 1976) 38 (22 Suppl 1):S161-S170, 2013

25. Smith JS, Lafage V, Schwab FJ, Shaffrey CI, Protopsaltis T, Klineberg E, et al: Prevalence and type of cervical deformity among 470 adults with throacolumbar deformity. Spine (Phila Pa 1976) 39:E1001-E1009, 2014

26. Smith JS, Shaffrey CI, Lafage V, Blondel B, Schwab F, Hos- tin R, et al: Spontaneous improvement of cervical alignment after correction of global sagittal balance following pedicle subtraction osteotomy. J Neurosurg Spine 17:300-307, 2012

27. Tang JA, Scheer JK, Smith JS, Deviren V, Bess S, Hart RA, et al: The impact of standing regional cervical sagittal alignment on outcomes in posterior cervical fusion surgery. Neurosurgery 71:662-669, 2012

28. Uchida K, Nakajima H, Sato R, Yayama T, Mwaka ES, Kobayashi S, et al: Cervical spondylotic myelopathy associated with kyphosis or sagittal sigmoid alignment: outcome after anterior or posterior decompression. J Neurosurg Spine 11:521-528, 2009

29. Villavicencio AT, Babuska JM, Ashton A, Busch E, Roeca C, Nelson EL, et al: Prospective, randomized, double-blind clinical study evaluating the correlation of clinical outcomes and cervical sagittal alignment. Neurosurgery 68:1309-1316, 2011

\section{Disclosure}

Funding for the International Spine Study Group Foundation, through which this study was conducted, is obtained through research grants from DePuy Spine and individual donations. Dr. Ames is an employee of UCSF. He is a consultant for DePuy, Stryker, and Medtronic. He has direct stock ownership in Doctors Research Group and Baxano Surgical. He is a patent holder for Fish \& Richardson, P.C. He receives royalties from Aesculap and Biomet Spine. Dr. Smith is a consultant for Biomet, NuVasive, Globus, Cerapedics, and DePuy Synthes. He receives royalties from Biomet and research support from DePuy-Synthes. He has received clinical or research support for this study (includes equipment or material) from DePuy-Synthes. Dr. Lafage has direct stock ownership in Nemaris and is a consultant for Medicrea. She receives research support from DePuy, SRS, ISSG, and NIH. She is a speaker/teacher for DePuy, K2M, NuVasive, and Nemaris. Dr. Schwab has direct stock ownership in Nemaris. He is a consultant for MSD, K2M, DePuy, and Medicrea. He receives research support from DePuy, MSD, and AOSpine. He is a patent holder for MSD, Nemaris, K2M, and NuVasive. He is a speaker/teacher for MSD, Nemaris, and K2M. Dr. Gupta has direct stock ownership in Johnson \& Johnson, Proctor and Gamble, Pfizer, and Pioneer. He is a consultant for DePuy-Synthes and Medicrea. He is treasurer for FOSA and a board member for SRS. Dr. Bess is a consultant for NuVasive, K2M, and Allosource. He has received clinical or research support for this study (includes equipment or material) from DePuy Spine and receives other research support from Medtronic and Innovasis. Dr. Mundis is a consultant for NuVasive, K2M, Misonix, and Medicrea. He is a board member for SOLAS. Dr. Klineberg receives speaker fees and fellowship research grants from DePuy-Synthes and AOSpine. He also received a fellowship grant from OREF. Dr. Protopsaltis is a consultant for Medicrea and Biomet Spine. He receives research support from Zimmer Spine. Dr. Shaffrey is a consultant for Biomet, Medtronic, NuVasive, and Stryker. He has direct stock ownership in NuVasive and is a patent holder for Biomet and NuVasive. He receives royalties from Biomet, Medtronic, and NuVasive.

\section{Author Contributions}

Conception and design: Ames. Acquisition of data: Lafage. Analysis and interpretation of data: Scheer. Drafting the article: Scheer. Critically revising the article: Scheer, Ames. Reviewed submitted version of manuscript: all authors. Approved the final version of the manuscript on behalf of all authors: Scheer. Statistical analysis: Scheer. Study supervision: Ames.

\section{Correspondence}

Justin K. Scheer, Department of Neurological Surgery, Northwestern University Feinberg School of Medicine, 676 N. St. Clair St., Ste. 2210, Chicago, IL 60611. email: jscheer@ucsd.edu. 